EGU21-10226

https://doi.org/10.5194/egusphere-egu21-10226

EGU General Assembly 2021

(c) Author(s) 2021. This work is distributed under

the Creative Commons Attribution 4.0 License.

\title{
Effects of flood-induced individual businesses' financial distress over complex cooperative productive systems
}

\author{
David Nortes Martínez ${ }^{1,2}$, Frederic Grelot ${ }^{2}$, Pauline Brémond ${ }^{2}$, Stefano Farolfi ${ }^{3,4}$, and Juliette \\ Rouchier $^{5}$ \\ ${ }^{1}$ CEMOI, Université de la Réunion, Saint-Denis de la Réunion, Réunion, France (david.nortes-martinez@univ-reunion.fr) \\ ${ }^{2} \mathrm{G}-\mathrm{EAU}$, Univ Montpellier, AgroParisTech, CIRAD, IRD, INRAE, Montpellier SupAgro, Montpellier, France \\ ${ }^{3}$ CIRAD, UMR G-EAU, 34398 Montpellier, France \\ ${ }^{4}$ Univ Montpellier, 34090 Montpellier, France \\ ${ }^{5}$ LAMSADE, CNRS, Paris, France
}

Today, flood risk management practices incorporate non-structural measures that take into account the potential of ecosystems to prevent, regulate and reduce water-related hazards. However, the implementation of non-structural measures, such as floodplains and water retention areas, increases the exposure of rural and farming areas for better protection of urban and industrial areas. Since agricultural enterprises are closely linked to land productivity, this exposure trade-off directly affects farm incomes, and thus the long-term sustainability of agricultural activities in floodplain and water retention areas. In addition, local businesses are increasingly interconnected in production networks and supply chains and impacts on local business can quickly have further consequences.

We propose to consider these supply networks as complex systems, i.e. a set of heterogeneous entities interacting with each other according to a given topology.In these systems, the upstream and downstream links that govern the interactions of the entities may allow the appearance of indirect effects that are reflected through the network of links. In our work, we focus on a cooperative winemaking system (CWS). A CWS is conceptualized as a supply chain in which a cooperative winery and a set of vinegrowers interact. The basic product of the system (the grape) is supplied by the vinegrowers, which the cooperative finishes processing (carrying out the winemaking, bottling and marketing stages).

We propose to analyze the extent to which individual winegrowers in financial difficulty may pose a threat to the sustainability of the system in the event of flooding. To carry out this analysis, we adopt a bottom-up approach. We use an agent-based model (the COOPER model) to simulate the production dynamics of the CWS. The COOPER model is used as a virtual laboratory to explore the behavior of the system under various flood scenarios, varying according to the spatial extent of the event and the season of occurrence. We test the influence of 4 parameters on financial viability at both the individual and system levels: the rigidity of the cost structure of the winery, the location of the winery, the individual business cessation criteria and the individual initial treasury. 
Our results show that winery-related parameters influence the capacity of both system and individuals to absorb flood impacts more than individual parameters. The analysis of financial flows shows that, indeed, contrary to standard hypotheses in cost-benefit analyses and business resilience studies, return to pre-disaster states might not be possible. Furthermore, without financial support, some businesses may never recover and bussines dismissal due to financial presures and harvest variations threats the survival of the CWS (hence theating the long term viability of farming activities). In addition, we unveil a mechanism to graduate the degree of damage spreading in case of productions losses within the CWS hidden in the revenue-cost sharing rules and the structure of costs. From a managerial point of view, this type of result has strong implications: managers can influence the capacity of the CWS to absorb shocks and prevent damage propagation by keeping cost structures from becoming too rigid. 